\title{
Çinko Üretimi Atık Kekinin Fosfat Adsorpsiyon Özelliklerinin İncelenmesi
}

\section{Investigation of Phosphate Adsorption Properties of Zinc Production Residue Cakes}

\author{
Geliş / Received: 11/02/2021
}

\author{
Harun Çiftçi ${ }^{1}$, Hasan Arslanoğlu ${ }^{2 *}$
}

Revize / Revised: 13/05/2021

Kabul / Accepted: 26/05/2021

ÖZ

Bu çalışmada Kayseri'de bulunan Çinkur işletmelerinde, çinko üretimi sırasında meydana gelen kurşunlu kek olarak adlandırılan, yüksek oranda kurşunun yanında çinko ve demir içeren artığın sulu ortamdan fosfat uzaklaştırılma şartları araştırılmıştır. Bu amaçla bu kekle sulu ortamdan fosfat giderilmesi üzerine, kek dozu, süre, ortam pH'sı ve sıcaklığı ve fosfat konsantrasyonu gibi parametrelerin etkileri incelenmiştir. Elde edilen sonuçlar kullanılarak adsorpsiyon izotermleri elde edilmiş ve bazı termodinamik büyüklükler hesaplanmıştır. Yapılan deneylerde fosfat giderme veriminin önemli ölçüde pH'ya ve kurşun keki dozuna bağlı olduğu bulunmuştur. Ayrıca fosfat uzaklaştırılmasının Langmuir ve Freundlich izotermine uyduğu, 120 dakikalık bir sürenin sonunda dengenin kurulduğu gözlenmiştir. Orijinal pH's1 7.69 olan 100 mg-P/L konsantrasyonundaki ortofosfat çözeltisinin, $30 \mathrm{~g} / \mathrm{L}$ dozunda kurşun kekiyle karıştırılıp 120 dakika temas ettirilmesiyle çözeltideki fosfatın yaklaşı $\%$ 75'i giderilebilmektedir.

Anahtar Kelimeler- Çinko Ekstraksiyon Atıkları, Kurşun Kekler, Fosfat Giderimi, Adsorpsiyon

\begin{abstract}
In this study, the conditions for removing phosphate from the aqueous environment of the residue containing zinc and iron in addition to lead, which is called as lead cake and formed during zinc production in çinkur plants in Kayseri was investigated. For this purpose, the effects of parameters such as cake dose, time, and environment $\mathrm{pH}$ and temperature and phosphate concentration on the removal of phosphate from aqueous environment with this cake were investigated. Using the obtained results, adsorption isotherms were obtained and some thermodynamic quantities were calculated. In the experiments, it was found that the phosphate removal efficiency is highly dependent on the $\mathrm{pH}$ and the lead cake dose. In addition, it was observed that phosphate removal complied with the Langmuir and Freundlich isotherm, and the equilibrium was established at the end of a period of 120 minutes. Approximately $75 \%$ of the phosphate in the solution can be removed by mixing the orthophosphate solution with a concentration of $100 \mathrm{mg}-\mathrm{P} / \mathrm{L}$ with an original $\mathrm{pH}$ of 7.69 with lead cake at a dose of $30 \mathrm{~g} / \mathrm{L}$ and contacting it for 120 minutes.
\end{abstract}

Keywords- Zinc Extraction Wastes, Lead Cakes, Phosphate Removal, Adsorption

1İletişim: harunciftci@yahoo.com (https://orcid.org/0000-0002-3210-5566)

Tıbbi Biyokimya Anabilim Dalı, Kırşehir Ahi Evran Üniversitesi, Tıp Fakültesi, 40100, Kırşehir

2*Sorumlu yazar iletişim: hasan.arslanoglu@ahievran.edu.tr (https://orcid.org/0000-0002-3132-4468)

Kimya Mühendisliği Bölümü, Kırşehir Ahi Evran Üniversitesi, Mühendislik-Mimarlık Fakültesi 40100, Kırşehir. 


\section{I.GİRIŞ}

Ötrofikasyon suların besi maddeleriyle zenginleşmesi ve bitki hayatının hareketli bir şekilde gelişmesi sonucu kalitenin kötüleşmesi ve suların ekolojik dengeyi kötü yönde etkilemesi olarak tanımlanabilir. Çoğu tatlı su göl ve nehir rezervlerinde sınıllayıcı nütrient fosfor $(\mathrm{P})$ ve antropojenik kaynaklardan bu elementlerin sulara geçişi, göllerin tabi yaşlanması süresinde oldukça yavaş yürüyen ötrofikasyon olayını hızlandırır. Göl ortamında meydana gelen bu olay neticesinde oluşan algler tarafindan var olan çözünmüş oksijen önemli ölçüde tüketilir. Çözünmüş oksijenin tüketilmesi balık ölümlerine yol açabilir ve bazı mavi yeşil algler balıkların ve bazen çiftlik hayvanlarının zehirlenmesine yol açabilir [1-6].

Fosfatların sularda meydana getirdiği bu kötü etkiler göz önüne alındığında, bunların sulara geçişini mümkün mertebe önleme zorunluluğu ortaya çıkmaktadır. Bunun için de öncelikle sular için fosfat kaynaklarının iyi bir şekilde belirlenmesi ve bu kaynaklardan yüzey sularına deşarj edilmeden önce fosfatların önemli ölçüde giderilmesi gerekir. Fosfat bileşikleri başta gübre endüstrisi olmak üzere, gıda, tekstil, metal kaplama, boya, deri ve deterjan endüstrilerinde yaygın olarak kullanılmaktadır. Gerek fosfat bileşiklerinin üretimi proseslerinde ve gerekse bu endüstriyel ürünlerin kullanılması sırasında alıcı ortamlara önemli miktarlarda fosfat karışmaktadır. Sularda kompleks anyonik yapıda bulunan fosfatlar, su ortamına genellikle polivalent metal tuzları ilave edilerek çözünmeyen türden fosfat bileşiklerine dönüştürülerek giderilir [7-9].

Yüzeysel sulara fosfatın geçişini sağlayan önemli kaynaklar tarımsal alanlardan ve çiftlik bölgelerinden gelen sızıntılar, evsel ve endüstriyel atık sular ve kentsel drenaj sızıntılarıdır. Fosfatların önemli bir kısmı evsel ve endüstriyel akımlar gibi noktasal kaynaklardan geçer. Bu kaynaklar noktasal olmayan kaynaklara göre daha kolay kontrol edilebilirler [10-12].

Yapılan araştırmalar evsel orjinli atıksularda fosfor konsantrasyonunun $5-30 \mathrm{mg} / \mathrm{L}$ seviyelerinde olduğunu göstermiştir. Hali hazırda kullanılan arıtım teknikleri, bu konsantrasyon sınılarına sahip atıksuların arıtımı için uygundur. Ancak özellikle kazan suyu ve bazı gıda endüstrisi atıksuları gibi yüksek fosfat içeren suların arıtımı özel tekniklere ihtiyaç duymaktadır. Normal seviyelerde fosfat içeren atıksuların arıtımı için pek çok araştırma yapılmıştır. Fosfat içeriği yüksek, özel atıksular için ekonomik arıtma proseslerine ihtiyaç vardır. Kullanılan mevcut fosfat arıtım teknolojilerinde genellikle mamül kimyasal maddeler kullanılmaktadır. Oysa arıtımda başka bir endüstrinin ekonomik değeri düşük bir atığının kullanılması maliyet yönünden prosesi cazip hale getirebilir [13-17].

Çalışmada Kayseri'de bulunan Çinkur tesislerinde çinkoüretimi sırasında döner filtre keki olarak adlandırılan ve oldukça büyük miktarlarda elde edilen artık maddenin yüksek konsantrasyonlarda fosfat içeren atık suların arıtımında kullanılabilme imkanları araştırılmıştır. Deneysel çalışmada, bu kekin adsorbant olarak kullanılmasıyla sulardan fosfat adsorpsiyonuna $\mathrm{pH}$, süre, konsantrasyon ve sıcaklık gibi faktörlerin etkileri incelenmiştir. Ayrıca elde edilen sonuçlar adsorpsiyon izotermlerine uygulanarak bazı termodinamik parametreler belirlenmiştir.

\section{MATERYAL VE METOT}

\section{A. Kurşun Kekinin Temini ve Hazırlanmast}

Deneylerde, Kayseri Çinkur ttesislerinden temin edilen çinko üretim artı̆̆ kurşun keki kullanıldı. Liç işlemi sonrasında meydana gelen bu kek önce, çözünerek ortama geçebilecek metal sülfatların uzaklaştırılması amacıyla 5 defa destile su ile yıkand. Kismen oda sıcaklı̆ğnda daha sonra ise $105^{\circ} \mathrm{C}^{\prime}$ deki etüvde kurutuldu, -200 mesh'lik elekten geçirildi ve ağzı kapaklı plastik şişelerde muhafaza edildi. Yapılan XRD ve SEM-EDX sonuçları Şekil 1 ve 2'de verilmiştir.

Çinko ekstraksiyon artığının kimyasal analizleri $\mathrm{LiBO}_{2}$ eritişi- $\mathrm{HNO}_{3}$ çözünürleştirmesi yöntemi ile gerçekleştirildi $[8,9]$. 


\begin{tabular}{|c|c|c|}
\hline & $\begin{array}{l}\text { BŞEÜ Fen Bilimleri Dergisi } \\
8(1), 251-262,2021\end{array}$ & $\begin{array}{r}\text { BSEU Journal of Science } \\
\text { https://doi.org/10.35193/bseufbd.878902 }\end{array}$ \\
\hline $\begin{array}{l}\text { KSEEY } \\
\text { VERS }\end{array}$ & & 2458-7575 (https://dergipark.org.tr/tr/pub/bseufbd) \\
\hline
\end{tabular}

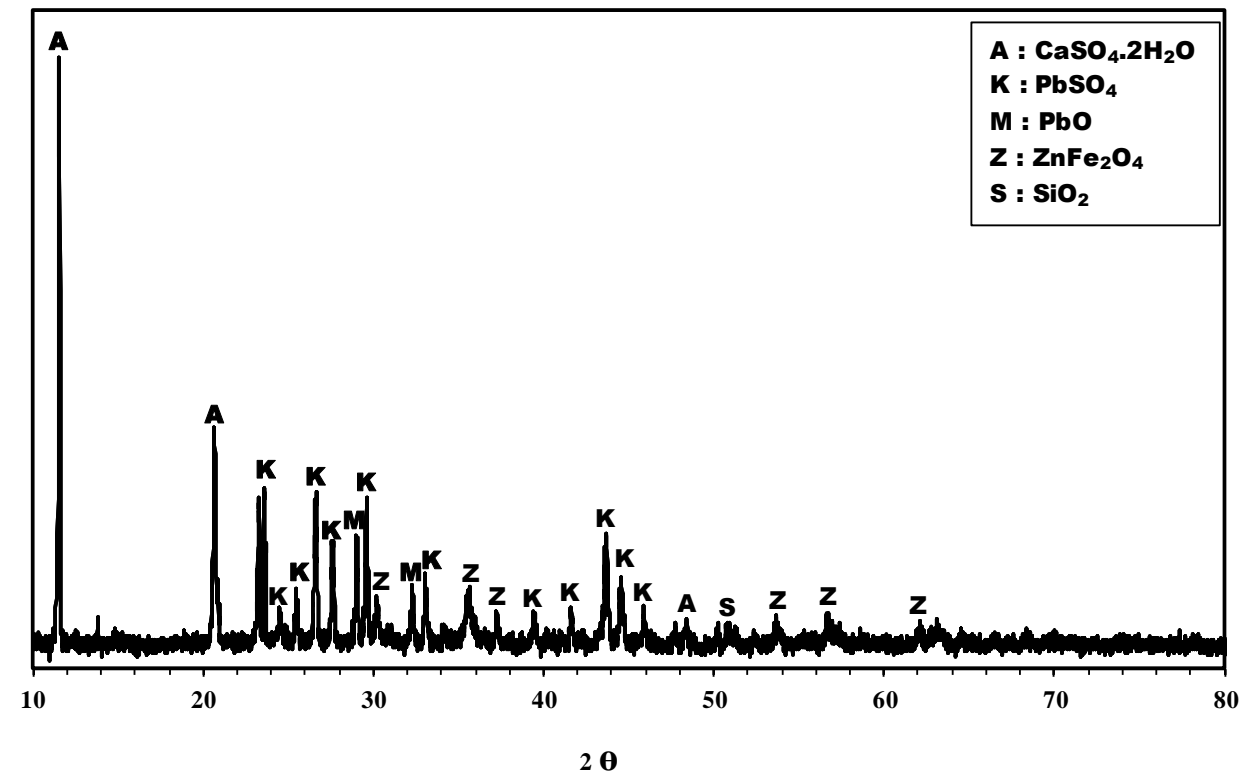

Şekil 1. Deneylerde kullanılan kurşun kekinin XRD diyagramı.
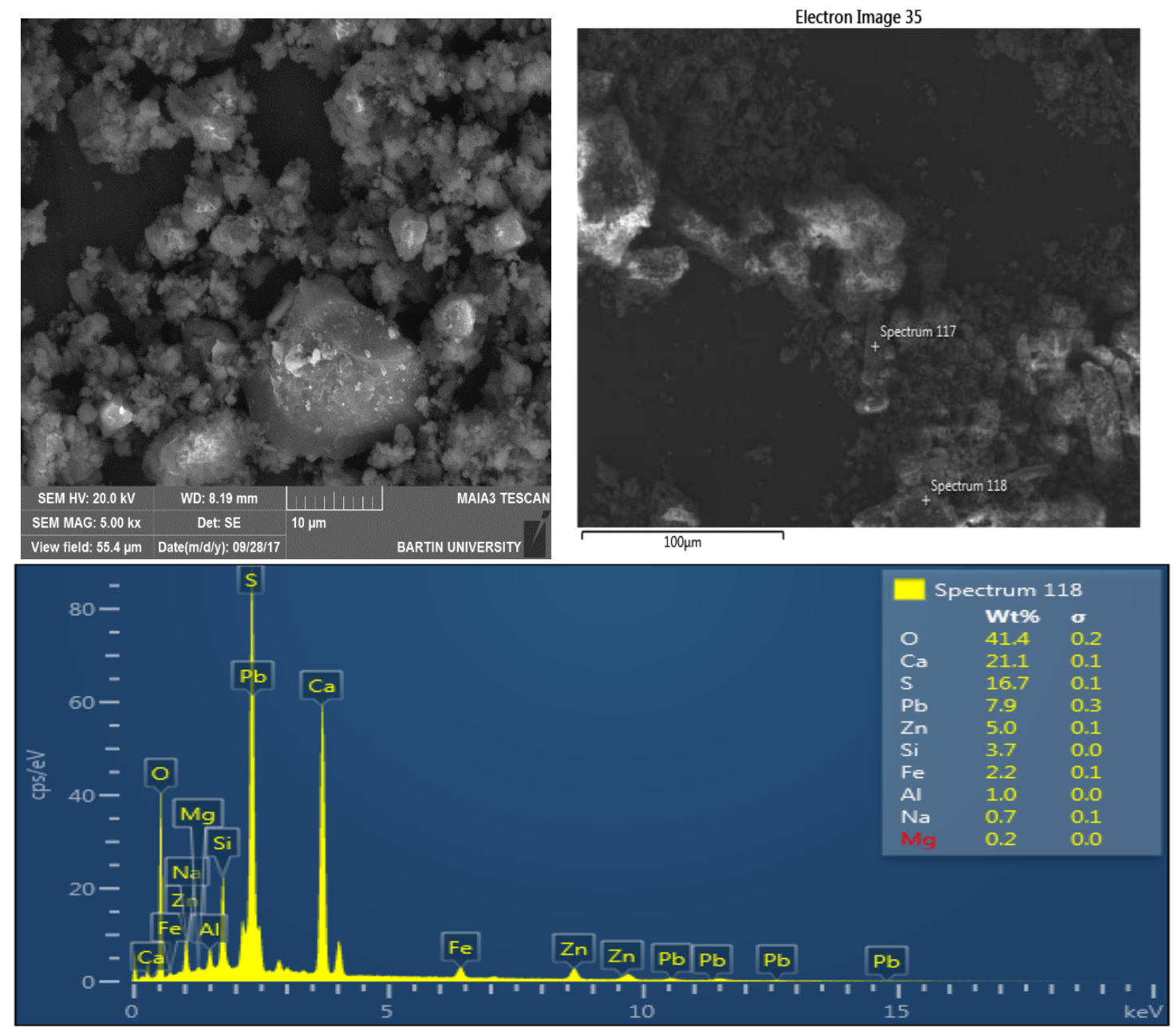

Şekil 2. Deneylerde kullanılan kurşun kekinin SEM görüntüsü ve EDX değerlendirmesi. 


\begin{tabular}{|c|c|c|}
\hline & $\begin{array}{l}\text { BŞEÜ Fen Bilimleri Dergisi } \\
8(1), 251-262,2021\end{array}$ & $\begin{array}{r}\text { BSEU Journal of Science } \\
\text { https://doi.org/10.35193/bseufbd.878902 }\end{array}$ \\
\hline $\begin{array}{l}\text { BiLCECKSYYH EDEBALI } \\
\text { ONIVERSITESI }\end{array}$ & & 2458-7575 (https://dergipark.org.tr/tr/pub/bseufbd) \\
\hline
\end{tabular}

\section{B. Fosfat Çözeltisinin Hazırlanması}

Deneysel çalışmada kullanılan fosfat çözeltileri $\mathrm{Na}_{2} \mathrm{HPO}_{4}$ tuzundan hazırlandı. Bu amaçla $14.314 \mathrm{~g}, \% 80$ saflıktaki $\mathrm{Na}_{2} \mathrm{HPO}_{4}$ tuzu tartıldı, bir miktar suda çözüldü ve daha sonra hacmi 500 ml'ye tamamlandı. Bu şekilde hazırlanan $5000 \mathrm{mg}-\mathrm{P} / \mathrm{L}$ 'lik konsantrasyonundaki standart stok çözelti uygun şekilde seyreltilerek deneylerde kullanıld. Seyreltmeler destile su ile yapıldı.

\section{Deneysel Çalışma}

Çalışmada önce adsorbent miktarının ve sürenin fosfat giderme üzerindeki verimi üzerine etkileri incelendi. Bunun için standart stok çözeltisinden $100 \mathrm{mg}-\mathrm{P} / \mathrm{L}$ konsantrasyonunda fosfat çözeltileri hazırlandı.

Bu çözeltilerin $100 \mathrm{~mL}$ 'si $150 \mathrm{~mL}$ 'lik erlenlere konuldu, bunlara 5-50 g arasında değişen miktarlarda kurşun keki ilave edilerek ağızları kapatıldı ve sıcaklığı $25^{\circ} \mathrm{C}$ 'deki çalkalayıcılı inkübatör (ZHCHENG ZHWY200 D) içerisine yerleştirildi. Örnekler, 10-240 dakika arasında değişen sürelerde, $400 \mathrm{rpm}$ hızla çalkalandı. Çalkalama işleminden sonra karışımlar mavi bant fillre kağıdından süzüldü. Süzüntülerde $\mathrm{pH}$ ölçümü, fosfor, çinko, kurşun, mangan, demir, kadmiyum ve kobalt analizleri yapıldı. Fosfor konsantrasyonu dikkate alınarak giderme yüzdeleri hesaplandı.

Fosfat konsantrasyonlarının etkisini belirlemek için başlangıç konsantrasyonları 100, 125, 150 mg-P/L olan fosfat çözeltileri ile değişen sürelerde fosfat giderme deneyleri yapıldı.

Daha sonra başlangıç pH'sının fosfat giderilmesi üzerine etkisini incelemek amacıyla, pH'sı 3-12 arasında değişen $100 \mathrm{mg}-\mathrm{P} / \mathrm{L}$ konsantrasyonundaki fosfat çözeltileri ile deneyler yapıldı.

Son olarak, konsantrasyonları 25-125 mg-P/L arasında değişen fosfat çözeltileriyle, daha önceki deneylerle belirlenen uygun $\mathrm{pH}$ ve dengeleme süresinde izoterm çalışması yapıldı.

Tüm deneyler ikişer paralel örnekte gerçekleştirildi ve $\pm \% 5$ uyum içerisindeki sonuçlar doğru kabul edilerek ortalaması alındı.

\section{Fosfat Analizleri}

Deneyler sırasında elde edilen süzüntülerde fosfatanalizleri Askorbik Asit yöntemine göre spektrofotometrik olarak yapıld1 [18].

\section{E. Metal Analizleri}

Bütün metal analizleri atomik absorbsiyon spektrofotometresi (Perkin Elmer Aanalyst 400) ile gerçekleştirildi. Uygun standartlar kullanılarak ve tayin aralığına seyreltilerek yapılan analizler sonucu, belirlenen metal konsantrasyonlarından geri hesap yapılarak metallerin çinko ekstaksiyon artığından liç yüzdeleri hesaplandı.

\section{SONUÇ VE TARTIŞMA}

Fosfat adsorpsiyonunda adsorbent olarak kullanılan kurşun kekinin bileşimi Tablo 1'de verilmiştir. Tablodan da görüldüğü gibi kullanılan örnek, \% $15.81 \mathrm{~Pb}, \% 8.52 \mathrm{Zn}$ ve \% 5.39 oranında $\mathrm{Fe}$ içermektedir. $\mathrm{Bu}$ bileşime göre içerdiği polivalent metal iyonlarından dolayı atık sulardaki bazı anyonik yapıdaki kompleks iyonları uzaklaştırabileceği fikrini doğurmaktadır. Bu çalışmada da sulu ortamdan kurşun keki kullanılarak fosfatın uzaklaştııılması araştııılmıştır. 


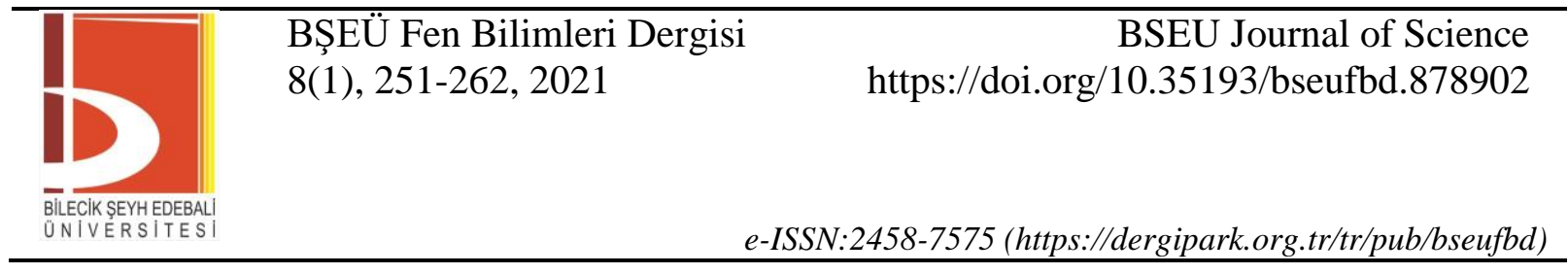

Tablo 1. Deneylerde kullanılan kurşun kekinin kimyasal bileşimi

\begin{tabular}{cc}
\hline Bileşen & Bileşim \\
\hline $\mathrm{Pb}$ & $\% 15.81$ \\
$\mathrm{Zn}$ & $\% 8.52$ \\
$\mathrm{Fe}$ & $\% 5.39$ \\
$\mathrm{Ca}$ & $\% 1.34$ \\
$\mathrm{Mn}$ & $2150 \mathrm{mg} / \mathrm{kg}$ \\
$\mathrm{Cd}$ & $317 \mathrm{mg} / \mathrm{kg}$ \\
$\mathrm{Cu}$ & $2289 \mathrm{mg} / \mathrm{kg}$ \\
$\mathrm{Ni}$ & $472 \mathrm{mg} / \mathrm{kg}$ \\
$\mathrm{Cr}$ & $245 \mathrm{mg} / \mathrm{kg}$ \\
\hline
\end{tabular}

Yapılan bazı ön çalışmalarda, kurşun kekinin sulu ortamlardan düşük konsantrasyonlardaki fosfatı etkin bir şekilde uzaklaştırdığı tespit edildi. Bu nedenle kurşun kekiyle, sulu ortamda bulunan yüksek konsantrasyondaki fosfatın uzaklaştırılmasının daha avantajlı olacağı düşünülmüştür. Bu düşünce doğrultusunda ilk deneyler kurşun keki miktarının süreye bağlı olarak fosfor gidermede etkisini ortaya koymak amacıyla $100 \mathrm{mg}-\mathrm{P} / \mathrm{L}$ konsantrasyonundaki fosfat çözeltileri ile yapıldı. $100 \mathrm{ml}$ fosfat çözeltisi, 5-50 g arsında değişen miktarlarda kurşun keki ile karıştırılarak, 10-240 dakika arasında değişen sürelerde çalkalandı. Analiz ve ölçümlerden hesaplanan fosfor giderme yüzdesi ve kek bünyesinden çözünerek çözeltiye geçen metal iyonu konsantrasyonları Şekil 3'de verilmiştir.

Artan kurşun keki miktarı ve süreyle, genel olarak fosfor giderme etkinliğinin arttığı ve tüm kek miktarları için yaklaşık olarak 120 dakika reaksiyon süresi sonunda bir dengeleme süresine erişildiği söylenebilir. Şekil 3'den çözelti ortamına kurşun kekinden çözünerek geçen metal iyonu konsantrasyonunun da kek miktarına bağlı olarak arttığı görülmektedir. Fosfor giderme yüzdesi dikkate alındığında $50 \mathrm{~g} / \mathrm{L}$ kurşun keki dozunun $100 \mathrm{mg} / \mathrm{L}$ konsantrasyonundaki fosforu uzaklaştırmak için uygun olduğu söylenebilir [19]. Ancak bir arıtım işleminin uygulanabilir olması için, söz konusu arıtımın en etkin bir şekilde yapılması yanı sıra proseste başka bir kirliliğin gelmemesi istenir. İşte bu nedenle kurşun kekinde çözeltiye geçen metal iyonu konsantrasyonlarının dikkate alınması gerekir.

Şekil 3 incelendiğinde, 50 g/L kurşun keki dozu kullanıldığında çözeltiye çok daha yüksek miktarlarda $\mathrm{Zn}$ ve $\mathrm{Pb}$ geçtiği görülmektedir. Örneğin, dengelenme süresi sonunda fosfor giderme yüzdesinin yine nispeten yüksek olduğu $30 \mathrm{~g} / \mathrm{L}$ kurşun keki dozu ile yapılan deneyde çözeltiye $0.82 \mathrm{mg} / \mathrm{L}$ kurşun ve $1.02 \mathrm{mg} / \mathrm{L}$ çinko geçerken, $50 \mathrm{~g} / \mathrm{L}$ dozu ile $0.92 \mathrm{mg} / \mathrm{L}$ kurşun ve $18.22 \mathrm{mg} / \mathrm{L}$ çinkonun geçtiği görülmektedir. Başka bir kirlenmeye neden olmamak amaciyla, $100 \mathrm{mg} / \mathrm{L}$ konsantrasyonundaki fosforu uzaklaştırmak için $30 \mathrm{~g} / \mathrm{L}$ dozunda kurşun kekinin kullanılmasının daha uygun olacağı söylenebilir.

İkinci aşamada, ortam pH'sının fosfat gidermedeki etkisi incelendi. Bunun için başlangıç pH'sı NaOH ve $\mathrm{H}_{2} \mathrm{SO}_{4}$ kullanılarak 3-12 arasında ayarlanan $100 \mathrm{mg} / \mathrm{L}$ konsantrasyonundaki fosfat çözeltilerine $30 \mathrm{~g} / \mathrm{L}$ dozunda kurşun keki kullanılarak 120 dakika çalkalandı. Elde edilen sonuçlar Şekil 4'de görülmektedir.

Başlangıç pH'sındaki artışa bağlı olarak fosfat giderme yüzdesi önemli ölçüde artmıştır. pH<6 bölgesinde toplam fosforun \%2-20'si giderilebilirken, $\mathrm{pH}>9$ 'da toplam fosforun \%80'ninden fazlası uzaklaştırılabilmektedir. Çözeltinin kendi orijinal pH'sı olan 7.69'da ise fosforun yaklaşık \%75'nin giderildiği görülmektedir [19]. Diğer taraftan kekten çözünerek çözeltiye geçen $\mathrm{Pb}$ iyonu konsantrasyonunun pH'nın artmasıyla arttığı görülmektedir. Çinko ise çözeltiye düşük pH'larda daha fazla geçmektedir. 

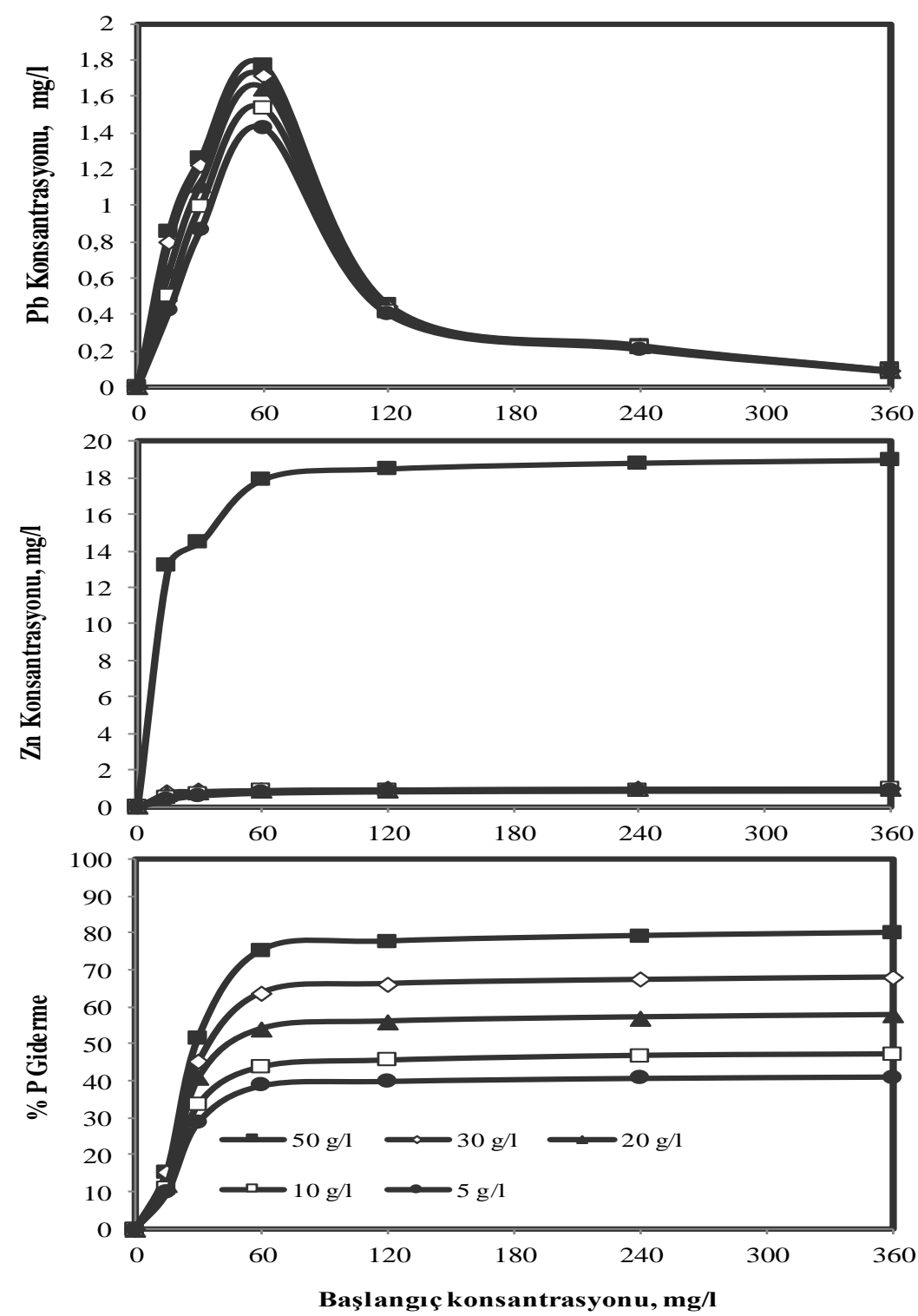

Şekil 3. Farklı kurşun keki dozu ile değişik sürelerde yapılan deneylerin sonuçları. [100 ml; 100mg-P/L; pH: 7.69; 25ํㅡ]

Çok düşük ve yüksek pH'ların gerek asit ve baz sarfiyatı ve gerekse suların nötral özelliğinin bozulması yüzünden pratik bir uygulanabilirliği yoktur. Şekil 4'ten en etkin fosfor gidermenin $\mathrm{pH}>10$ 'da olduğu görülmektedir. Ancak, bu durumda çözeltiye konsantrasyon limitlerinin çok üzerinde $\mathrm{Pb}$ ve $\mathrm{Zn}$ 'nin geçtiği görülmektedir. Bu tür bir ikincil kirliliği önlemek ve alkali sarfiyatının ortadan kaldırmak amacıyla işlemin kendi pH'sında yapılmasının, proses ekonomisi ve uygulanabilirlik açısından daha uygun olduğu söylenebilir. Bu nedenle diğer parametrelerin fosfat adsorpsiyonu üzerine etkisinin incelendiği deneyler, çözeltinin orijinal pH'ında yürütüldü. 

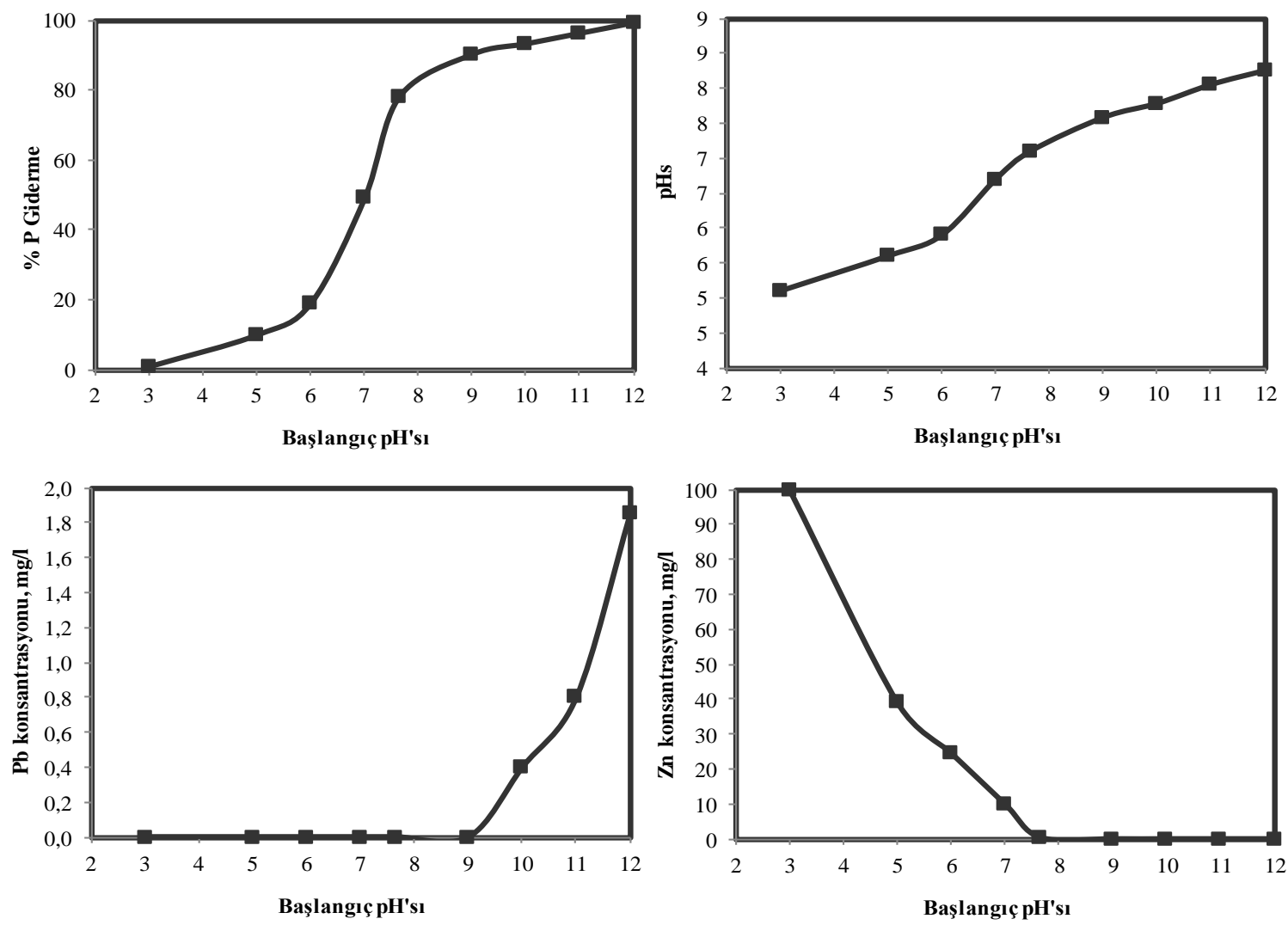

Şekil 4. Kurşun keki ile fosfat adsorpsiyonu üzerine başlangıç pH’sının etkisinin incelendiği deney sonuçları. [100 ml; $100 \mathrm{mg}-\mathrm{P} / \mathrm{L}$; $30 \mathrm{~g} / \mathrm{L}$ kurşun keki; 120 dakika temas süresi; $\left.25^{\circ} \mathrm{C}\right]$.

Şekil 5'de fosfat adsorpsiyonu üzerine başlangıç fosfat konsantrasyonunun etkisi verilmiştir. Fosfat konsantrasyonunun artışına bağlı olarak giderme yüzdesi düşmekte, ancak birim adsorbent (kurşun keki) başına uzaklaşan fosfat miktarı artmaktadır. Ayrıca yaklaşık 100-120 dakikalık sürenin sonunda tüm konsantrasyonlar için bir dengelenme süresine erişilmektedir. Örneğin $100 \mathrm{mg}-\mathrm{P} / \mathrm{L}$ konsantrasyonundaki fosfat çözeltilerinde, dengelenmenin olduğu 120 dakika sonunda yaklaşık \%74.98'lik bir adsorpsiyon meydana gelirken, bu değer 125 ve $150 \mathrm{mg}-\mathrm{P} / \mathrm{L}$ konsantrasyonları için sırasıyla \%66.17 ve \%48.98 olmaktadır [20].

Başlangıç konsantrasyonları farklı olan fosfat çözeltilerinin $30 \mathrm{~g} / \mathrm{L}$ dozunda, optimum pH'da ve 120 dakika süreyle kurşun keki ile temas ettirilmesi sonucunda elde edilen veriler Langmuir ve Freundlich izotermlerine uygulandı (Eşitlik (1) ve (2)) [19, 20].

Farklı sıcaklıklarda yapılan fosfat adsorpsiyonu sonrasında elde edilen Langmuir izotermi şekil 6'da verilmiştir. Lineer regrasyon kullanılarak izotermlerin eğim ve kaymasından b ve $\mathrm{Q}^{0}$ değerleri hesaplandı. Eşitlik (3)'e göre ln b değerlerinin 1/T değerlerine karşı grafiğe geçirilmesiyle adsorpsiyon entalpisi $-11.5941 \mathrm{~kJ} / \mathrm{mol}$ olarak bulundu. Eşitlik (4) ve (5) kullanılarak farklı sıcaklıklardaki adsorpsiyon serbest entalpisi ve entropi değişimleri hesaplandı. Sonuçlar Tablo 2'de görülmektedir. 


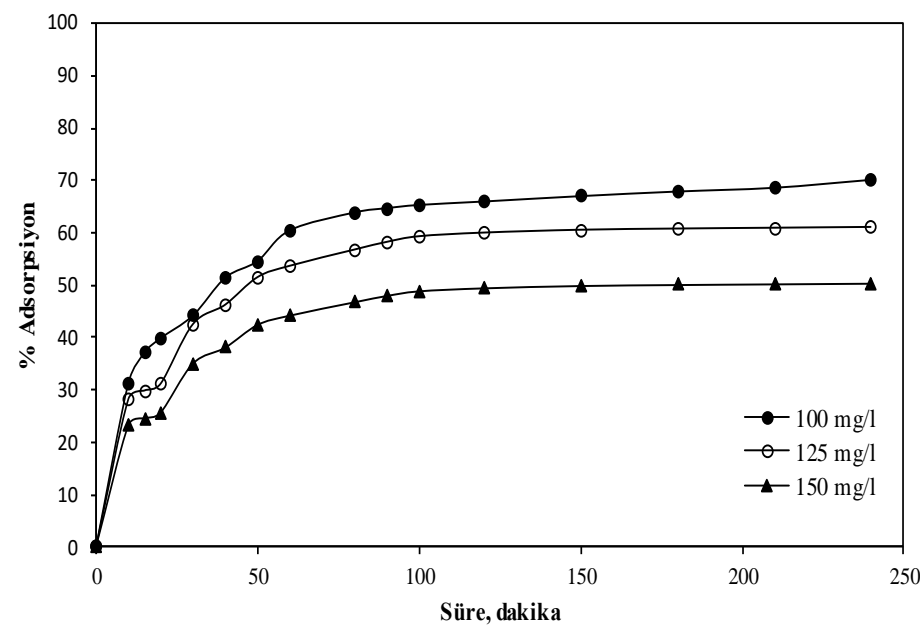

Şekil 5. Kurşun keki ile fosfat adsorpsiyonu üzerine başlangıç fosfor konsantrasyonunun etkisi. [100 mL; $30 \mathrm{~g} / \mathrm{L}$ kurşun keki; $\mathrm{pH}: 7.69 ; 25^{\circ} \mathrm{C}$ ].

$$
\begin{aligned}
& \frac{C_{\mathrm{e}}}{q_{\mathrm{e}}}=\frac{1}{q_{\max } b}+\frac{C_{\mathrm{e}}}{q_{\max }} \\
& \ln (x / m)=\ln K_{\mathrm{f}}+\frac{1}{n} \ln C_{\mathrm{e}} \\
& \operatorname{lnb}=\ln \mathrm{b}^{\prime}-\Delta \mathrm{H} / \mathrm{RT} \\
& \ln (1 / \mathrm{b})=\Delta \mathrm{G} / \mathrm{RT} \\
& \Delta \mathrm{G}=\Delta \mathrm{H}^{\circ}-\mathrm{T} \Delta \mathrm{S}
\end{aligned}
$$

Eşitliklerde $x$ : Adsorplanan madde miktarı (mg), $m$ : Adsorbent miktarı (g), $C_{e}$ : Adsorplananın çözeltideki denge konsantrasyonunu $(\mathrm{mg} / \mathrm{L})$ göstermektedir. $K_{\mathrm{f}}(\mathrm{mg} / \mathrm{g})$ adsorpsiyon kapasitesinin bir ölçüsü olan Freundlich sabitidir. Diğer Freundlich sabiti $\mathrm{n}$ ise boyutsuzdur. q $\mathrm{q}_{\max }$ : Maksimum adsorpsiyon kapasitesi, (mg/g), b: adsorpsiyon enerjisi ile ilgili bir sabit, (L/mg). $T$, mutlak sicaklık $(K)$ ve $R$ üniversal gaz sabitidir $\left(8.314 \mathrm{Jmol}^{-1} \mathrm{~K}^{-}\right.$ $\left.{ }^{1}\right)$. Adsorpsiyon prosesinin serbest enerji $\left(\Delta G^{o}\right)$, entalpi $\left(\Delta H^{\circ}\right)$ ve entropi $\left(\Delta S^{\circ}\right)$ değişimi gibi termodinamik parametreleri yukarıdaki eşitliklerle hesaplanabilir.

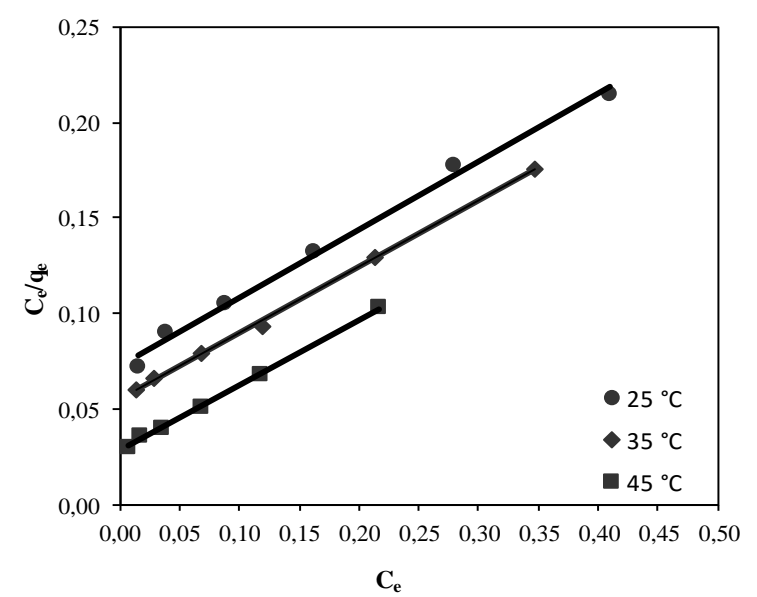

Şekil 6. Kurşun keki ile fosfat adsorpsiyonu için Langmuir izotermi. [100 ml; 25-125 mg-P/L; 30 g/L kurşun keki; pH: 7.69; 120 dakika temas süresi] 
Fosfat adsorpsiyonu için hesaplanan adsorpsiyon entalpisinin negatif işaretli oluşu adsorpsiyon olayının ekzotermik olduğunu göstermektedir. Ayrıca izotermlerin eldesi esanasında yapılan sıcaklık çalışmalarında artan sıcaklıkla fosfat giderme yüzdesinin düşmesi de olayın ekzotermik olduğunu kanıtlamaktadır. Tablo 2'de kurşun keki ile fosfatadsorpsiyonun serbest entalpi değişiminin negatif olduğu görülmektedir. Bu durum fosfatın keke adsorpsiyonunun kendiliğinden meydana gelen bir olay olduğunu göstermektedir [19-21].

Tablo 2. Langmuir sabitleri ve termodinamik sabitler

\begin{tabular}{cccccc}
\hline $\begin{array}{c}\text { Sicaklık } \\
{ }^{\mathbf{0}} \mathbf{C}\end{array}$ & \multicolumn{2}{c}{ Langmuir } & & $\begin{array}{c}\Delta \mathbf{G} \\
\mathbf{b} \mathbf{J} / \mathbf{m o l})\end{array}$ & $\begin{array}{c}\Delta \mathbf{S} \\
(\mathbf{k J} / \mathbf{m o l})\end{array}$ \\
\cline { 2 - 3 } $\mathbf{2 5}$ & 0.3371 & 2.6441 & 5.479 & \\
$\mathbf{3 5}$ & 0.2312 & 2.3463 & 5.433 & 0.02 \\
$\mathbf{4 5}$ & 0.1049 & 2.2104 & 5.109 & \\
\hline
\end{tabular}

Her sıcaklık için elde edilen izoterm verileri Freundlich eşitliğine uygulanmıştır. $\ln (\mathrm{x} / \mathrm{m})$ değerlerinin $\ln \mathrm{C}$ değerlerine karşı grafiğe geçirilmesiyle elde edilen doğrular, sonuçların Freundlich izotermine uygulanabilir olduğunu göstermektedir (Şekil 7). Sicaklığa bağlı olarak elde edilen Freundlich sabitleri Tablo 3'de verilmiştir. Tablodan da görüldüğü gibi adsorpsiyon kapasitesinin bir ölçüsü olan Freundlich sabiti $\mathrm{K}_{\mathrm{f}}$, artan sicaklıkla azalmaktadır.

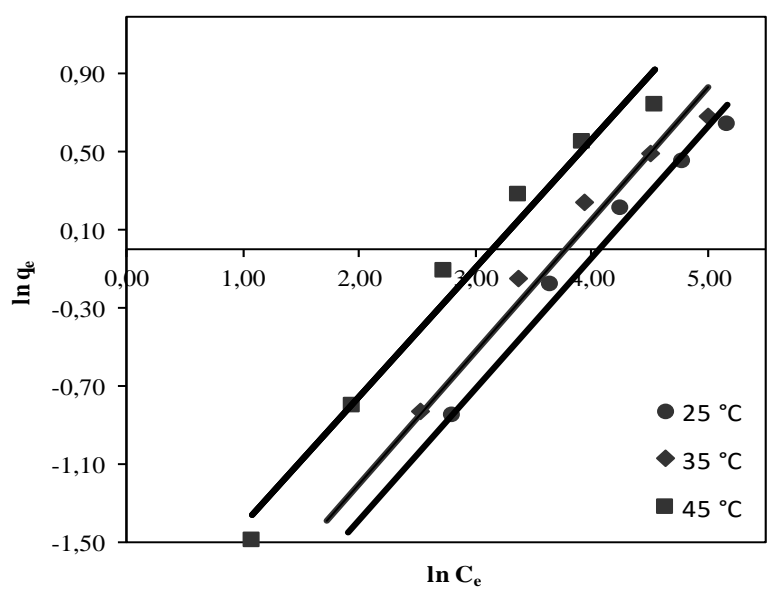

Şekil 7. Kurşun keki ile fosfat adsorpsiyonu için Freundlich izotermi. [100 mL; 25-125 mg-P/L; 30 g/L kurşun keki; pH: 7.69; 120 dakika temas süresi]

Tablo 3. Freundlich sabitleri

\begin{tabular}{cccc}
\hline Sicaklık, ${ }^{\circ} \mathbf{C}$ & $\mathbf{n}$ & $\mathbf{1 / n}$ & $\mathbf{K}_{\mathbf{f}}$ \\
\hline $\mathbf{2 5}$ & 2.404 & 0.416 & 0.654 \\
$\mathbf{3 5}$ & 3.176 & 0.315 & 0.682 \\
$\mathbf{4 5}$ & 2.632 & 0.380 & 0.436 \\
\hline
\end{tabular}

Langmuir izotermlerinden elde edilen maksimum tek tabaka kapasitesi $25^{\circ} \mathrm{C}$ 'de $25-125 \mathrm{mg}-\mathrm{P} / \mathrm{L}$ başlangıç konsantrasyonu aralığında ve $30 \mathrm{~g} / \mathrm{L}$ dozunda $2.644 \mathrm{mg} / \mathrm{g}$ olmaktadır. Sicaklı̆̆ın artmasıyla adsorpsiyon kapasitesi düşmekte ve $45^{\circ} \mathrm{C}$ 'deki şartlarda fosfat adsorpsiyon kapasitesi $2.210 \mathrm{mg} / \mathrm{g}$ olmaktadır.

Çok sayıda çalışma, fosfatı gidermek için adsorbanları kullandı ve hem kinetik hem de denge ile ilgili çalı̧̧ma parametrelerini elde etti. Tablo 4 adsorpsiyon çalışmalarında elde edilen adsorpsiyon kapasitelerini 
göstermektedir. Fosfatı gidermek için kullanılan çinko atık keki Tablo 4'deki çoğu malzemegibi uygunadsorpsiyon kapasitesine sahiptir. Çinko atık kekinin sulu çözeltilerden fosfatın çıkarılması için kullanılabileceğini göstermektedir.

Table 4. Literatürde bildirilen bazı malzemelerin adsorpsiyon kapasiteleri.

\begin{tabular}{lcc}
\hline Adsorbent & $\begin{array}{c}\text { Adsorpsiyon } \\
\text { kapasitesi } \\
\mathbf{~ m g ~ g} \\
(\mathbf{q}\end{array}$ & Referans \\
\hline Sentetik magnetit & 11.78 & {$[22]$} \\
Bentonite & 8.33 & {$[23]$} \\
Sentetik demir oksit & 5.03 & {$[24]$} \\
Biochar & 12.8 & {$[25]$} \\
Zenginleştirilmiş Magnetit & 6.41 & {$[26]$} \\
Bazik oksijen firın cürufu adsorpsiyonunun özellikleri ve mekanizmaları & 3.71 & {$[27]$} \\
Çinko atık keki & 2.65 & Bu çalışma \\
\hline
\end{tabular}

\section{SONUÇLAR}

Karbonatlı cevherlerden çinko ekstrakte edildikten sonra kalan kurşunlu keklerin fosfat adsorpsiyon özelliklerinin araştırıldığı bu çalışmada genel olarak aşağıdaki sonuçlar bulunmuştur.

Ortofosfattan hazırlanan 100 mg-P/L konsantrasyonundaki çözeltilerle, $30 \mathrm{~g} / \mathrm{L}$ kurşun keki dozunda ve $25^{\circ} \mathrm{C}$ 'de yapılan dengeleme süresi çalışmasında 120 dakika sonra dengenin sağlandığı bulunmuştur. Bu şartlarda ortamdaki fosfatın yaklaşık $\% 75$ 'i giderilmektedir.

Değişik pH'larda yapılan deneylerin sonucunda, $\mathrm{pH}$ 'nın yükselmesiyle kurşun kekinin daha fazla fosfat uzaklaştırdığı bulunmuştur. Fosfat giderme etkinliği kuvvetli alkali ortamlarda (pH 10-12) daha yüksektir. Ancak bunun pratik bir önemi yoktur.

Farklı sıcaklıklarda ve değişik başlangıç fosfat konsantrasyonlarındaki çözeltilerle yapılan deneyler sonucunda, fosfat giderilmesi $25-125 \mathrm{mg}-\mathrm{P} / \mathrm{L}$ konsantrasyon aralığında Langmuir ve Freundlich izotermlerine uymaktadır. Buna ilişkin yapılan hesaplamalarda; Langmuir tek tabaka adsorpsiyon kapasitesi $25^{\circ} \mathrm{C}$ de, 2.6441 $\mathrm{mg} / \mathrm{g}$ adsorbent olarak bulunmuştur. Sicaklığa bağlı olarak adsorpsiyon etkinliği düşmektedir. Adsorpsiyon entalpisinin negatif oluşu olayın ekzotermik olduğunu göstermektedir. Serbest entalpi değişimlerinin negatif oluşu olayın ortofosfatın kurşun kekine adsorpsiyonunun kendiliğinden meydana gelen bir olay olduğunu göstermektedir.

Nihai bir sonuç olarak, ortofosfatın kurşun kekine etkin bir şekilde adsorbe olduğu söylenebilir. Ancak önceden yıkanarak çözünebilir çinko ve kurşun kalıntılarının giderilmiş olmasına rağmen, kurşun kekinden çözelti ortamına çinko ve kurşun iyonu geçebilir. Nitekim sonuçlar bunu göstermektedir.

Bu nedenle bu materyal, atıksulardan fosfat uzaklaştırılmasında kullanılamaz. Zira bu defa da bu ikincil kirleticilerin uzaklaştırılmasına ihtiyaç vardır. Ortamda kurşun ve çinko iyonlarının bulunmasının mahsur teşkil etmediği durumlarda fosfat uzaklaştırılmasında göz önüne alınabilir.

\section{KAYNAKLAR}

[1] Kuroki, V., Bosco, G. E., Fadini, P. S., Mozeto, A. A., Cestari, A. R. \& Carvalho, W. A. (2014). Use of a La (III)-modified bentonite for effective phosphate removal from aqueous media. Journal of hazardous materials, 274, 124-131.

[2] Diao, J., Shao, L., Liu, D., Qiao, Y., Tan, W., Wu, L. \& Xie, B. (2018). Removal of phosphorus from leach liquor of steel slag: Adsorption dephosphorization with activated alumina. JOM, 70(10), 2027-2032.

[3] Xiong, J., He, Z., Mahmood, Q., Liu, D., Yang, X. \& Islam, E. (2008). Phosphate removal from solution using steel slag through magnetic separation. Journal of hazardous materials, 152(1), 211-215. 
[4] Kondalkar, M., Fegade, U., Attarde, S. \& Ingle, S. (2019). Phosphate removal, mechanism, and adsorption properties of Fe-Mn-Zn oxide trimetal alloy nanocomposite fabricated via co-precipitation method. Separation Science and Technology, 54(16), 2682-2694.

[5] Fan, R., Chen, C. L., Lin, J. Y., Tzeng, J. H., Huang, C. P., Dong, C. \& Huang, C. P. (2019). Adsorption characteristics of ammonium ion onto hydrous biochars in dilute aqueous solutions. Bioresource technology, $272,465-472$.

[6] Jang, J. \& Lee, D. S. (2019). Effective phosphorus removal using chitosan/Ca-organically modified montmorillonite beads in batch and fixed-bed column studies. Journal of hazardous materials, 375, 9-18.

[7] Yoshida, H. \& Galinada, W. A. (2002). Equilibria for adsorption of phosphates on OH- type strongly basic ion exchanger. AIChE Journal, 48(10), 2193-2202.

[8] Altundoğan, H. S. \& Tümen, F. (2002). Removal of phosphates from aqueous solutions by using bauxite. I: Effect of $\mathrm{pH}$ on the adsorption of various phosphates. Journal of Chemical Technology \& Biotechnology: International Research in Process, Environmental \& Clean Technology, 77(1), 77-85.

[9] Altundoğan, H. S. \& Tümen, F. (2003). Removal of phosphates from aqueous solutions by using bauxite II: the activation study. Journal of Chemical Technology \& Biotechnology: International Research in Process, Environmental \& Clean Technology, 78(7), 824-833.

[10] Li, Y., Liu, C., Luan, Z., Peng, X., Zhu, C., Chen, Z. \& Jia, Z. (2006). Phosphate removal from aqueous solutions using raw and activated red mud and fly ash. Journal of hazardous materials, 137(1), 374-383.

[11] Liu, Y., Sheng, X., Dong, Y. \& Ma, Y. (2012). Removal of high-concentration phosphate by calcite: effect of sulfate and pH. Desalination, 289, 66-71.

[12] Karageorgiou, K., Paschalis, M. \& Anastassakis, G. N. (2007). Removal of phosphate species from solution by adsorption onto calcite used as natural adsorbent. Journal of Hazardous Materials, 139(3), 447-452.

[13] Li, M., Liu, J., Xu, Y. \& Qian, G. (2016). Phosphate adsorption on metal oxides and metal hydroxides: A comparative review. Environmental Reviews, 24(3), 319-332.

[14] Liu, H., Sun, X., Yin, C. \& Hu, C. (2008). Removal of phosphate by mesoporous $\mathrm{ZrO}_{2}$. Journal of hazardous materials, 151(2-3), 616-622.

[15] Huang, W., Wang, S., Zhu, Z., Li, L., Yao, X., Rudolph, V. \& Haghseresht, F. (2008). Phosphate removal from wastewater using red mud. Journal of hazardous materials, 158(1), 35-42.

[16] Yin, H., Yun, Y., Zhang, Y. \& Fan, C. (2011). Phosphate removal from wastewaters by a naturally occurring, calcium-rich sepiolite. Journal of Hazardous Materials, 198, 362-369.

[17] Nguyen, T. A. H., Ngo, H. H., Guo, W. S., Zhang, J., Liang, S., Lee, D. J. \& Bui, X. T. (2014). Modification of agricultural waste/by-products for enhanced phosphate removal and recovery: potential and obstacles. Bioresource technology, 169, 750-762.

[18] APHA-AWWA/WEF. (1998). Standard Methods for the Examination of Water and Wastewater, 20th Edition. American Public Health Association, Washington DC, USA.

[19] Arslanoğlu, H. (2021). Production of low-cost adsorbent with small particle size from calcium carbonate rich residue carbonatation cake and their high performance phosphate adsorption applications. Journal of Materials Research and Technology, 11, 428-447.

[20] Eren, M. Ş., Arslanoğlu, H. \& Çiftçi, H. (2020). Production of microporous Cu-doped BTC (Cu-BTC) metalorganic framework composite materials, superior adsorbents for the removal of methylene blue (Basic Blue 9). Journal of Environmental Chemical Engineering, 8(5), 104247.

[21] Arslanoğlu, H., Kaya, S. \& Tümen, F. (2020). Cr (VI) adsorption on low-cost activated carbon developed from grape marc-vinasse mixture. Particulate Science and Technology, 38(6), 768-781.

[22] Shahid, M. K., Kim, Y. \& Choi, Y. G. (2019). Magnetite synthesis using iron oxide waste and its application for phosphate adsorption with column and batch reactors. Chemical Engineering Research and Design, 148, 169-179.

[23] Yaghoobi-Rahni, S., Rezaei, B. \& Mirghaffari, N. (2017). Bentonite surface modification and characterization for high selective phosphate adsorption from aqueous media and its application for wastewater treatments. Journal of Water Reuse and Desalination, 7(2), 175-186.

[24] Yoon, S. Y., Lee, C. G., Park, J. A., Kim, J. H., Kim, S. B., Lee, S. H. \& Choi, J. W. (2014). Kinetic, equilibrium and thermodynamic studies for phosphate adsorption to magnetic iron oxide nanoparticles. Chemical engineering journal, 236, 341-347.

[25] Trazzi, P. A., Leahy, J. J., Hayes, M. H. \& Kwapinski, W. (2016). Adsorption and desorption of phosphate on biochars. Journal of environmental chemical engineering, 4(1), 37-46.

[26] Shahid, M. K., Kim, Y. \& Choi, Y. G. (2019). Adsorption of phosphate on magnetite-enriched particles (MEP) separated from the mill scale. Frontiers of Environmental Science \& Engineering, 13(5), 1-12. 


\begin{tabular}{|c|c|c|}
\hline & $\begin{array}{l}\text { BŞEÜ Fen Bilimleri Dergisi } \\
8(1), 251-262,2021\end{array}$ & $\begin{array}{r}\text { BSEU Journal of Science } \\
\text { https://doi.org/10.35193/bseufbd.878902 }\end{array}$ \\
\hline$V E R$ & & :2458-7575 (https://dergipark.org.tr/tr/pub/bseufbd) \\
\hline
\end{tabular}

[27] Xue, Y., Hou, H. \& Zhu, S. (2009). Characteristics and mechanisms of phosphate adsorption onto basic oxygen furnace slag. Journal of Hazardous Materials, 162(2-3), 973-980. 